\title{
Context-dependent effects of marine protected areas on predatory interactions
}

\author{
S. Clemente ${ }^{1,2, *}$, J. C. Hernández ${ }^{1}$ A. Brito ${ }^{1}$ \\ ${ }^{1}$ Biodiversidad, Ecología Marina y Conservación, Departamento de Biología Animal (Ciencias Marinas), Facultad de Biología, \\ Universidad de La Laguna, Avenida Francisco Sánchez s/n, 38206 La Laguna, Tenerife, Islas Canarias, Spain \\ ${ }^{2}$ Present address: Biology Department, Villanova University, 800 Lancaster Ave., Villanova, Pennsylvania 19085, USA
}

\begin{abstract}
We studied the effects of marine protected areas (MPAs) on predatory interactions at a regional scale of 3 different islands across the geographical gradient of the Canary Islands. Protection measures positively affected predatory fish assemblages, enhancing the intensity of predatory interactions in comparison to equivalent unprotected areas (UAs), and causing indirect effects on populations of the key herbivorous sea urchin Diadema aff. antillarum. Results of tethering experiments and the strong negative correlation found between predation rate and prey density strongly suggest that predation controls sea urchin populations. Overall urchin density was lower in MPAs than in UAs; however, species composition of predatory fish assemblages and the size of sea urchin effectively preyed upon differed significantly between studied islands, as did urchin size-frequency distributions. Only in locations where key predatory species (balistids, diodontids and large labrid species) were present was there the potential to promote top-down control on sea urchins. The present study shows the importance of both protection measures and environmental context to enhance the strength of predatory fish activity. Protection under different contexts can produce different consequences of predation interactions, even over relatively small spatial scales. Therefore, regional and local-scale environmental gradients should not be overlooked as a factor affecting the occurrence and magnitude of predatory interactions in benthic marine communities, especially in systems that are markedly variable at small scales.
\end{abstract}

KEY WORDS: Diadema aff. antillarum • Marine protected areas · Environmental context . Predation intensity $\cdot$ Tethering experiments $\cdot$ Escape size $\cdot$ Canary Islands

\section{INTRODUCTION}

In marine environments, fishing activities have historically targeted large-bodied predators, in many cases leading to severe population declines or even extinctions (Jackson et al. 2001, Worm et al. 2006) that alter the equilibrium of the ecosystem and trigger dominance shifts (Steneck 1998, Pinnegar et al. 2000, Steneck et al. 2002). Sea urchins are recognised worldwide as important grazers in benthic communities of sublittoral rocky reefs, acting as the key herbivore in many systems (Sala et al. 1998, Guidetti 2006, Hernández et al. 2008a, Ling 2008). Despite the complexity of food webs in subtidal ecosystems, relationships between predatory fish and sea urchins are easily affected by fishing activities (McClanahan \& Shafir 1990, Steneck 1998, Guidetti \& Sala 2007). It has been suggested that protection from fishing would aid the recovery of fish populations and re-establish predatory interactions that control urchin populations, both in temperate (Sala \& Zabala 1996, Sala et al. 1998, Shears \& Babcock 2002, Guidetti 2006, 2007, Guidetti \& Sala 2007, Clemente et al. 2009) and tropical ecosystems (McClanahan \& Shafir 1990, Brown-Saracino et al. 2007, Harborne et al. 2009).

Fishing is restricted in marine protected areas (MPAs), which therefore function as large-scale ecosystem experiments (Pinnegar et al. 2000) where the 
density and size of predators tend to be elevated (NRC 2001). Indirect effects of management are widely expected to occur (Pinnegar et al. 2000, Halpern 2003), thus enabling comparisons of the outcomes of trophic interactions between MPAs and unprotected areas (UAs), and providing a framework to test how responses vary with environmental conditions (Shears et al. 2008). Natural forces interact with anthropogenic impacts in shaping marine ecosystems, so natural variability in physical conditions and assemblages should be integrated when analysing the effects of human uses of marine resources (Micheli et al. 2005). Predatory assemblages, for example, vary as a function of many biotic and abiotic factors (Power 1992), and the strength of their predatory control over sea urchin populations can markedly change following oscillations of environmental factors (e.g. temperature or productivity) or what we refer to as environmental context (Steneck et al. 2002, Shears et al. 2008). Understanding the context-dependent nature of predatory impacts over urchin abundances is therefore pivotal in predicting the strength of species interactions at contrasting levels of protection. The outcomes of protection measures over predator-prey interactions are therefore not straightforward to predict (Guidetti \& Sala 2007), and studies assessing how predatory control varies as a function of both protection and environmental conditions are still scant (Micheli et al. 2005, Frank et al. 2006, Guidetti \& Dulčić 2007, Shears et al. 2008). The topic deserves further attention in order to appropriately predict the consequences of large-scale changes in species distribution, especially in a world where human activities are accelerating species loss (Jackson et al. 2001).

Benthic communities in the Canary Islands, similarly to other temperate and subtropical regions, are often characterised by 1 of 2 alternative community states: productive macroalgal beds, or barren grounds that are dominated by encrusting coralline algae due to the intense grazing activity of the sea urchin Diadema aff. antillarum (Hernández et al. 2008a,b). Sea surface temperature (SST) has been recently found to strongly influence settlement of Diadema aff. antillarum (Hernández et al. 2010), so a pattern of distribution of the species following the temperature-related gradient that occurs across the Canary Islands (Barton et al. 1998) would be expected. SST varies from east to west of the archipelago by $\sim 2^{\circ} \mathrm{C}$ (see Fig. $\mathrm{S} 1$ in the supplement at www.int-res.com/articles/suppl/m437p119 _supp.pdf). However, specific studies evaluating population dynamics of the sea urchin on different islands found non-temperature-related patterns of recruitment or adult urchin density at this spatial scale (Hernández et al. 2008a, Clemente et al. 2009). These results suggested that population control was more likely related to post-settlement processes, among which predation is known to be a main source of mortality (Hunt \& Scheibling 1997, Hereu et al. 2004). In this region, the triggerfishes Balistes capriscus and Canthidermis sufflamen, the diodontid Chilomycterus reticulata, and the labrid Bodianus scrofa are recognised as keystone predators of sea urchins and have the potential to effectively control urchin abundance. These species, along with juvenile sea urchin consumers, such as large-sized individuals of the sea breams Diplodus cervinus and Diplodus sargus and the wrasse Thalassoma pavo, are the only predatory fish known to actively prey upon Diadema aff. antillarum (Clemente et al. 2010).

Biogeographical differences in fish assemblages throughout the Canaries are widely known, and many fish species have specific habitat affinities that generate temperature-related patterns of distribution (Bortone et al. 1991, Falcón et al. 1996, Tuya et al. 2004). Species with warmer-water affinities (i.e. sea urchin predators Balistes capriscus, Canthidermis sufflamen and Chilomycterus reticulata) prevail in the western islands and those with more temperate affinities (i.e. Diplodus cervinus and Diplodus sargus) in the eastern islands (Brito et al. 1995, Falcón et al. 1996), with potential contrasting effects of predatory interactions on sea urchin populations. These patterns suggest that the interaction between predatory fish and urchins is likely to depend on both the incidence of fishing and the environmental context. The present study aimed to assess the role of predation upon the sea urchin Diadema aff. antillarum across the fishing-intensity and oceanographic gradient over the regional geographic range off the Canary Islands. Effects of protection from fishing were evaluated in 3 MPAs and adjacent UAs, which encompass different environmental conditions found at the extremes of the east-to-west gradient of the archipelago. Specifically, we explored (1) the distribution patterns of major fish predators of the sea urchin; (2) the density, size structure and degree of refuge utilisation of Diadema aff. antillarum; and (3) the predation intensity upon the sea urchin in sublittoral rocky reefs. The effect of urchin size on predation intensity was also tested, as larger urchins are expected to be less susceptible, especially where large predators are depleted. We hypothesised that the efficacy of fishing restrictions to enhance predatory interactions would not be consistent across the contrasting environmental conditions due to context-dependent variations in assemblages of predatory fish. Most efficient urchin predators are species with warmer-water affinities (Clemente et al. 2010), so protection would especially be expected to aid predation control of urchin populations on the western islands of the archipelago. 


\section{MATERIALS AND METHODS}

Study area. The present study was carried out in shallow rocky bottoms around the Canary Islands during the period April to November 2005. The eastern boundary of the archipelago is separated from the African coast by $90 \mathrm{~km}$ and it extends about $400 \mathrm{~km}$ further west. This geographical location between the cool, nutrient-rich waters from the northwest African coastal upwelling and the warmer, nutrient-poor open ocean waters means the Canary Islands are considered a coastal transition zone (Barton et al. 1998). An oceanographic gradient is found across the archipelago where differences in nutrients, primary productivity and SST occur from east to west (Barton et al. 1998) (see Fig. S1 in the supplement). Therefore, the islands' marine assemblages consist of a combination of tropi$\mathrm{cal}$, subtropical and temperate species that varies according to its location within the oceanographic gra- dient and creates an exceptional experimental scenario (Falcón et al. 1996, Hernández et al. 2008a). Rocky bottoms of similar benthic complexity (medium topographic relief of 1 to $3 \mathrm{~m}$; see Hernández et al. 2008a for details) at 3 of the 7 islands within the temperature gradient of the archipelago were monitored; from west to east: El Hierro $\left(22.01^{\circ} \mathrm{C}\right)$, La Palma $(21.68$ ${ }^{\circ} \mathrm{C}$ ), and Lanzarote and its northern islets (herafter Lanzarote-islets) $\left(20.46^{\circ} \mathrm{C}\right)$ (mean annual SST from NCEP/NCAR reanalysis data; Kalnay et al. 1996) (see Fig. S1 in the supplement). Moreover, these islands include the 3 MPAs of the region: La Restinga-Mar de Las Calmas (14 yr old; 775 ha), La Palma (9 yr; 3719 ha) and La Graciosa e Islotes al Norte de Lanzarote (15 yr; 70700 ha) respectively (our Fig. 1; see Hernández et al. 2008b for detailed descriptions of the MPAs). Four protected sites within each MPA and 4 comparable nonprotected sites on each island were studied (Fig. 1). UAs were chosen along the east or southwest coast-
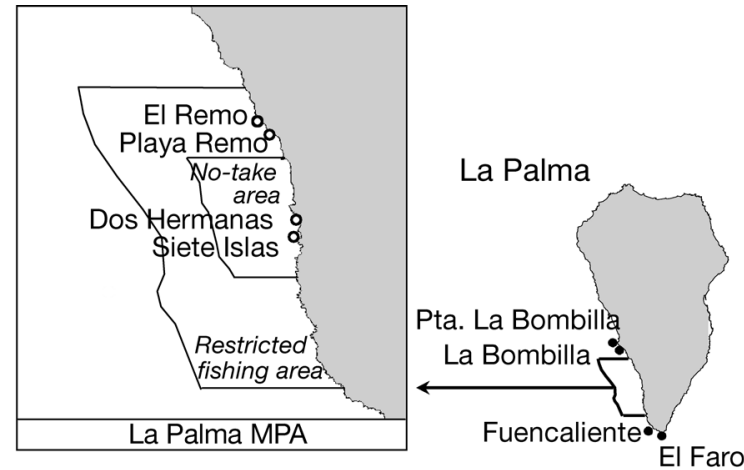
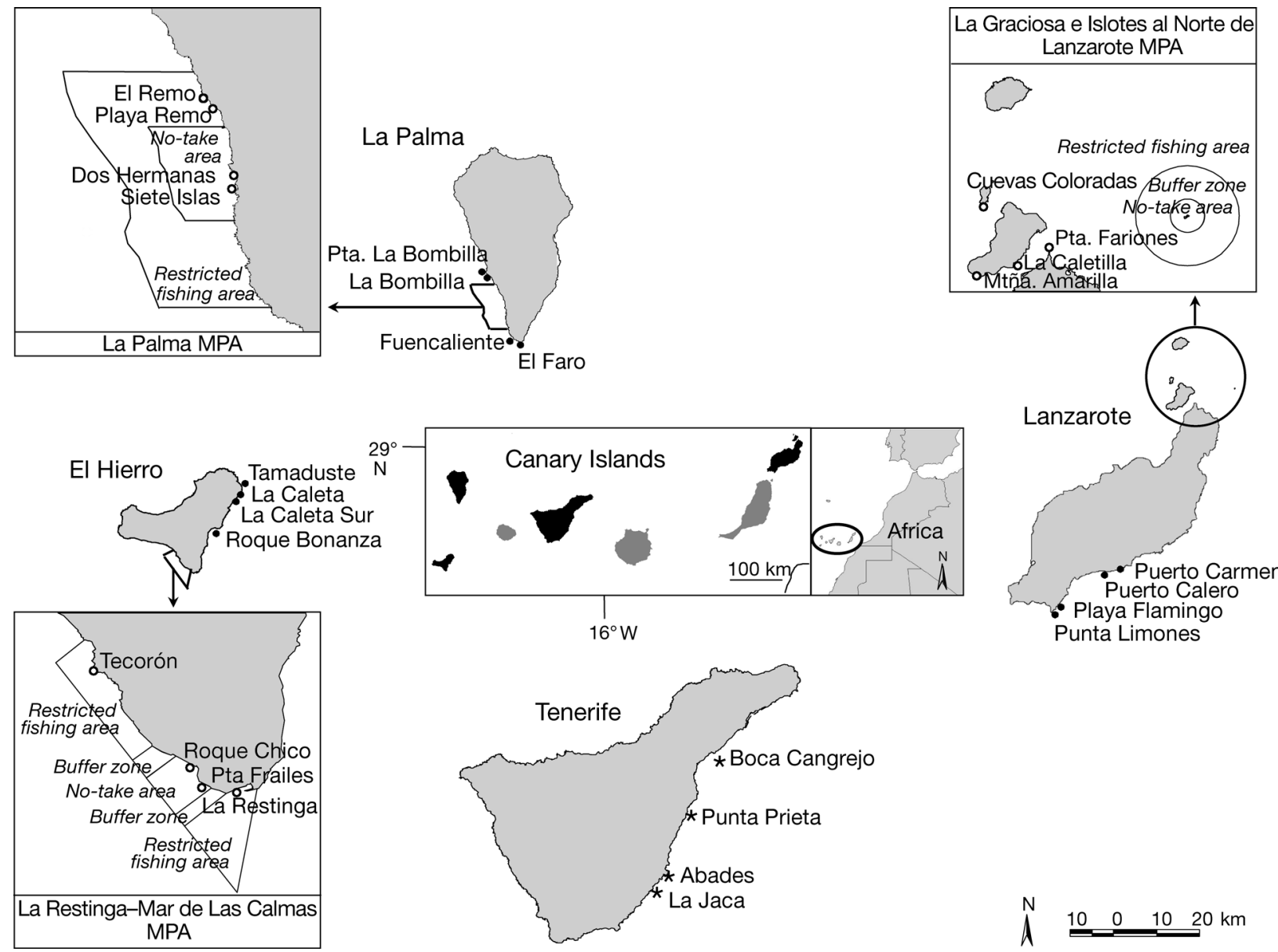

Fig. 1. Study sites across the Canary Islands in the 3 marine protected areas (MPAs; o) of La Restinga-Mar de Las Calmas, La Palma and La Graciosa e Islotes al Norte de Lanzarote (from west to east); and in the nearby unprotected areas (UAs; $\bullet$ ). Sites in UAs of Tenerife $(*)$ were surveyed by Clemente et al. (2007a) 
lines of each island, with similar environmental conditions, experiencing low wave-exposure levels (Hernández et al. 2008a) and far enough away from the MPAs to rule out the possibility of territorial predatory fish spill-over.

Abundance patterns of predatory fish. Densities of Diadema aff. antillarum fish predators (Clemente et al. 2010) were estimated using an in situ stationary visual method. We followed the point-count method in which the observer takes a position at the centre of a circle $\left(100 \mathrm{~m}^{2}\right)$, recording the number and size $( \pm 1 \mathrm{~cm})$ of individuals of each species for $5 \mathrm{~min}$ (Bortone et al. 1989). At each site, 6 randomly selected replicates of this procedure were conducted. As in previous studies evaluating populations of urchin predatory fish (Guidetti 2006), juvenile stages were excluded from assessments, as their numerical contribution may strongly influence density estimates while having no predatory effect on urchins. Also, only large Diplodus sargus $(>30 \mathrm{~cm})$ and Thalassoma pavo $(>12 \mathrm{~cm})$ and medium-large Diplodus cervinus $(>30 \mathrm{~cm})$ were considered, as they are the only sizes known to prey on Diadema aff. antillarum (Clemente et al. 2010).

Diadema aff. antillarum: patterns of abundance, size and refuge utilisation. The belt transect method was used to estimate urchin density (Hernández et al. 2008a). A total of 8 to 10 transects of $10 \times 2 \mathrm{~m}$ were run parallel to the coastline between 5 and $15 \mathrm{~m}$ depth. Along each transect, a $1 \mathrm{~m}^{2}$ quadrat was randomly placed, and test diameters of urchins within each quadrat were measured $( \pm 1 \mathrm{~mm})$. In addition, it was noted whether individuals were located in a crevice (cryptic position), or were openly grazing the substratum without physical protection (exposed position). This information was used as a measure of urchins' level of exposure to predators (Nelson \& Vance 1979, Sala \& Zabala 1996, Shears \& Babcock 2002).

Predation levels on sea urchins. We evaluated predation levels using tethering experiments (Clemente et al. 2007a), previously used to test predation intensity on sea urchins in tropical (McClanahan \& Muthiga 1989) and temperate systems (Sala \& Zabala 1996, Shears \& Babcock 2002, Guidetti 2006, Pederson \& Johnson 2006, Bonaviri et al. 2009). Diadema aff. antillarum individuals of 3 different size classes (20$30 \mathrm{~mm}, 30-40 \mathrm{~mm}$ and $40-50 \mathrm{~mm}$ ) were tethered to lines fixed to the substratum. As handling this longspined species becomes difficult, a tagging technique that used external tags anchored in the urchin tests, previously applied to $D$. aff. antillarum and tested for artefacts (Clemente et al. 2007b), was employed. Ten tagged individuals of each size class were attached at $1 \mathrm{~m}$ intervals along transect lines laid over 5 to $10 \mathrm{~m}$ deep rocky reefs at each site (see details in Clemente et al. 2007a). Experiments were visited every $24 \mathrm{~h}$ over
$5 \mathrm{~d}$ to determine the number of consumed individuals and classify the condition of the carcass. Carcasses were found to be either (1) gone, with only the nylon tether present-unknown source of predation that may be due to consumption by sparids or labrids that often consume urchins whole (McClanahan 1995, Clemente et al. 2010); (2) broken-attributable to fish such as balistids that methodically break open the carcass (McClanahan 1995, Clemente et al. 2010); or (3) intact, with patches of freshly stripped spinesattributable to predation by the starfish Coscinasterias spp. or Marthasterias spp. (Shears \& Babcock 2002, Bonaviri et al. 2009).

A survival rate $(\mathrm{S})$ was calculated as the number of days each individual survived in the experiment, and a predation rate calculated as the total length of the experiment (5 d) minus the survival rate. A relative predation intensity index (PI) was computed by dividing each individual predation rate by the duration of the experiment in days: $\mathrm{PI}=(5-\mathrm{S}) / 5$. Averages of the index at each site produced values between 0 (no urchins eaten over the experiment) and 1 (all individuals eaten during the first experimental day) (McClanahan \& Shafir 1990). Cumulative percentages of Diadema aff. antillarum preyed upon during the course of the experiments were calculated for each combination of island and protection level.

Statistical treatment of data. A comparison of predatory fish assemblages' structure (composition and abundance) was made using a distance-based permutational multivariate analysis of variance (PERMANOVA) with 4999 permutations (Anderson 2004), and Bray-Curtis similarities, calculated among logarithmically transformed data. A 3-way design in which 'Protection' (2 levels) and 'Island' (3 levels) were treated as fixed factors and 'Site' was nested within the interaction of 'Protection' and 'Island' (random, 24 levels) was used. Obtained significant effects were examined in more detail using canonical analysis of principal coordinates (CAP) with the leave-one-out approach to test the goodness of fit (Anderson \& Willis 2003). Species responsible for the obtained differences were identified by the strength of their correlation with the canonical axis, providing a good indication of which species should be further investigated using univariate analysis (Anderson \& Willis 2003). Only species correlations of $|\mathrm{r}|>0.4$ were considered significant (Anderson \& Willis 2003).

Univariate analyses on density data of fish predators found significant with CAP, as well as on Diadema aff. antillarum densities and relative predation indexes, were compared with distance-based permutational ANOVAs using Euclidean distances of raw data and 4999 permutations of the appropriate exchangeable units (Anderson 2004). Three-way designs as de- 
scribed in the previous paragraph were conducted when analysing predatory species abundances and urchin densities. A 4-way design was performed when analysing relative predation index, in which 'Urchin size' (3 levels) was also included as a fixed factor. Significant terms in the full models were examined individually using a posteriori pairwise comparisons by permutations (Anderson 2004). The software PRIMER 6 and PERMANOVA+ was used for all procedures.

Differences in Diadema aff. antillarum size distribution between levels of protection were analysed by frequency analyses $\left(\chi^{2}\right)$. Relationships between fish predation intensity (excluding predation events attributable to starfishes) and relevant parameters for each study site (predatory fish density, sea urchin density, and percentage of exposed urchins) were assessed. Correlation analysis was used to explore the relationship between predation intensity and urchin density. When using predation index or percentage of exposed urchins (proportional data) as response variables, generalised linear models (GLM) were fitted to our data with a binomial error distribution and a logit link function. Log transformations of independent variables were used to obtain curvilinear adjusts. Data obtained by Clemente et al. (2007a) in highly fished areas off the central Tenerife island (Fig. 1) were included in the analyses to get a more realistic sense of the variability across the archipelago. Correlations were performed with SPSS-15.0, and GLM with R software 2.13.0 (www.R-project.org).

\section{RESULTS}

\section{Distribution patterns of predatory fish assemblages}

The PERMANOVA showed that the assemblage structure of predatory fish differed significantly between levels of 'Protection' and more strongly between studied islands (Table 1A). Differences in patterns of fish assemblages between MPAs and UAs were consistent east to west across the archipelago. In addition, $a$ posteriori pairwise analyses illustrated that species density and composition of predatory fish assemblages at El Hierro and La Palma were significantly different from those at Lanzarote-islets (Table 1A). CAP analyses supported these results, finding significant effects of both factors 'Protection' ( $\left.\delta^{2}=0.176 ; \mathrm{p}<0.01\right)$ and 'Island' $\left(\delta^{2}=0.273 ; \mathrm{p}<0.01\right)$ (Table 2). The constrained ordination testing for differences among islands indicated that predatory fish assemblages surveyed at Lanzarote-islets largely tended to cluster together and differed somewhat from assemblages at the other 2 islands (Fig. 2). However, an important degree of overlap, especially between assemblages at El Hierro and
La Palma, was also detected (Fig. 2). Correlations of species with the canonical axes indicated that differences in predatory fish assemblages among levels of protection were primarily due to Bodianus scrofa (Table 2A), whereas main species driving the differences between islands were Balistes capriscus, Canthidermis sufflamen and Thalassoma pavo (Table 2B, Fig. 2). The latter correlations showed that results at Lanzarote-islets were mainly due to a decrease in the density of most fish predatory species, whereas they dominated in differing magnitude in El Hierro and La Palma. Increases in densities of $C$. sufflamen in El Hierro and of Balistes capriscus and T. pavo in La Palma contributed to differentiate somewhat the predatory assemblages at both islands (Fig. 2). The leaveone-out approach showed that the most dissimilar island regarding assemblages of predatory fish was Lanzarote-islets, with the highest allocation success, while the relatively high percentage of misclassification among El Hierro and La Palma indicated that these islands were more similar to one another (Table 2).

Univariate ANOVAs showed that densities of the balistids Balistes capriscus and Canthidermis sufflamen varied significantly between studied islands, with both species achieving higher densities in the western islands of El Hierro and La Palma than in Lanzarote-

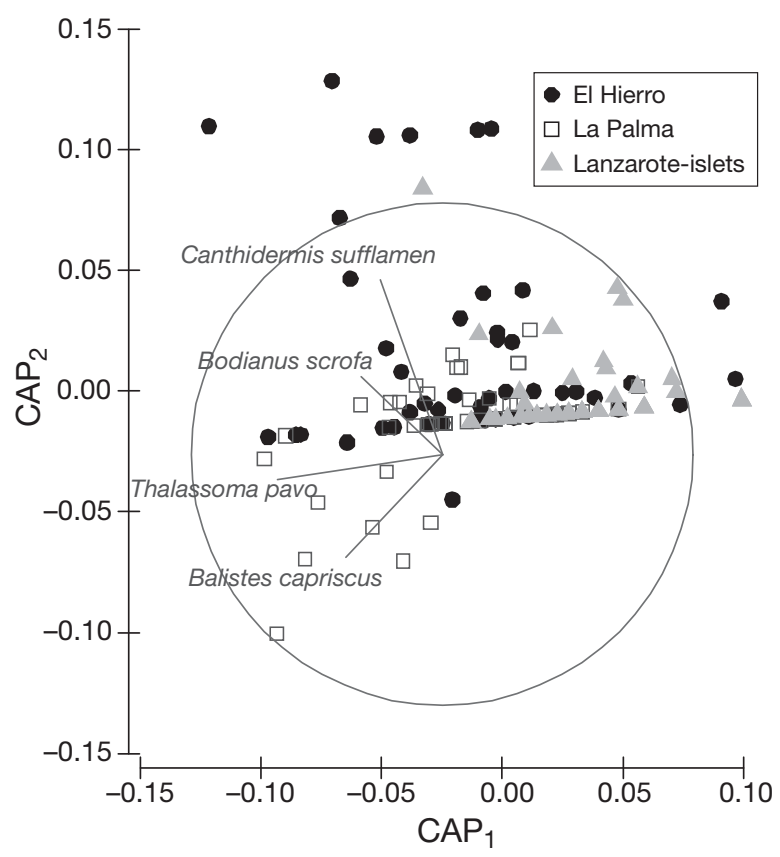

Fig. 2. Biplot of the first 2 canonical axes of canonical analyses of principal coordinates (CAP) examining the effects of the factor 'Island' on assemblages of predatory fish of Diadema aff. antillarum in the Canary Islands. Vectors represent correlations between the axes of the principal coordinate analysis and original fish species variables responsible for differences among groups, identified by a strength of correlation with the axis of $|\mathrm{r}|>0.4$ 
islets to the east (Table 1B,C, Fig. 3A). In addition, a significant effect of the factor 'Protection' on Balistes capriscus abundances was found, with overall fish densities higher in the MPAs than in the UAs (Table 1B, Fig. 3A). Abundances of the labrid Bodianus scrofa sig- nificantly differed in response to the level of protection, with higher fish densities in MPAs across the archipelago (Table 1D, Fig. 3B). The factor 'Island' was found to have a significant effect on densities of the other species of the family, Thalassoma pavo, which

Table 1. Three-way distance-based permutational multivariate (PERMANOVA) and univariate analyses of variance (ANOVAs) assessing differences between marine protected and unprotected areas, islands, and sites within each island of the Canary Islands, and protection level for (A) log-transformed multivariate abundance data of predatory fish assemblages of Diadema aff. antillarum; and densities of predatory fish (B) Balistes capriscus, (C) Canthidermis sufflamen, (D) Bodianus scrofa and (E) Thalassoma pavo. Respective pairwise comparisons are included. ns: not significant; ${ }^{*} \mathrm{p}<0.05_{;}{ }^{* *} \mathrm{p}<0.01$

\begin{tabular}{|c|c|c|c|c|c|}
\hline Source of variation & df & SS & MS & $F$ & $\mathrm{p}($ perm $)$ \\
\hline \multicolumn{6}{|c|}{ (A) Predatory fish assemblages } \\
\hline Protection & 1 & 4737.20 & 4737.20 & 3.72 & * \\
\hline Island & 2 & 14727.00 & 7363.50 & 5.78 & ** \\
\hline Protection $\times$ Island & 2 & 2491.20 & 1245.60 & 0.98 & ns \\
\hline Site $($ Protection $\times$ Island) & 18 & 22924.00 & 1273.60 & 1.58 & ** \\
\hline Residual & 120 & 98582.00 & 804.85 & & \\
\hline \multirow[t]{5}{*}{ Total } & 143 & $1.41 \times 10^{5}$ & & & \\
\hline & Island & $\mathbf{T}$ & p (perm) & & \\
\hline & El Hierro vs. La Palma & 1.56 & ns & & \\
\hline & El Hierro vs. Lanzarote-islets & 2.48 & $* *$ & & \\
\hline & La Palma vs. Lanzarote-islets & 2.67 & $* *$ & & \\
\hline \multicolumn{6}{|l|}{ (B) Balistes capriscus } \\
\hline Protection & 1 & 2.25 & 2.25 & 6.57 & * \\
\hline Island & 2 & 2.39 & 1.19 & 3.49 & ${ }^{*}$ \\
\hline Protection $\times$ Island & 2 & 2.16 & 1.08 & 3.16 & ns \\
\hline Site $($ Protection $\times$ Island) & 18 & 6.17 & 0.34 & 1.27 & ns \\
\hline Residual & 120 & 32.33 & 0.27 & & \\
\hline \multirow[t]{5}{*}{ Total } & 143 & 45.31 & & & \\
\hline & Island & $\mathbf{T}$ & p (perm) & & \\
\hline & El Hierro vs. La Palma & 0.28 & ns & & \\
\hline & El Hierro vs. Lanzarote-islets & 7.34 & ** & & \\
\hline & La Palma vs. Lanzarote-islets & 2.05 & * & & \\
\hline \multicolumn{6}{|l|}{ (C) Canthidermis sufflamen } \\
\hline Protection & 1 & 0.06 & 0.06 & 0.82 & ns \\
\hline Island & 2 & 0.79 & 0.40 & 5.18 & ${ }^{*}$ \\
\hline Protection $\times$ Island & 2 & 0.04 & 0.02 & 0.27 & ns \\
\hline Site $($ Protection $\times$ Island $)$ & 18 & 1.37 & 0.08 & 1.49 & ns \\
\hline Residual & 120 & 6.17 & 0.05 & & \\
\hline \multirow[t]{5}{*}{ Total } & 143 & 8.44 & & & \\
\hline & Island & $\mathbf{T}$ & p (perm) & & \\
\hline & El Hierro vs. La Palma & 2.28 & ns & & \\
\hline & El Hierro vs. Lanzarote-islets & 7.35 & ** & & \\
\hline & La Palma vs. Lanzarote-islets & 2.1 .0 & * & & \\
\hline \multicolumn{6}{|l|}{ (D) Bodianus scrofa } \\
\hline Protection & 1 & 1.56 & 1.56 & 6.96 & * \\
\hline Island & 2 & 0.67 & 0.33 & 1.48 & ns \\
\hline Protection $\times$ Island & 2 & 0.67 & 0.33 & 1.48 & ns \\
\hline Site (Protection $\times$ Island) & 18 & 4.04 & 0.22 & 2.57 & ** \\
\hline Residual & 120 & 10.50 & 0.09 & & \\
\hline Total & 143 & 17.44 & & & \\
\hline \multicolumn{6}{|l|}{ (E) Thalassoma pavo } \\
\hline Protection & 1 & 427.11 & 427.11 & 0.87 & ns \\
\hline Island & 2 & 11181.00 & 5590.30 & 11.40 & ${ }^{* *}$ \\
\hline Protection $\times$ Island & 2 & 238.43 & 119.22 & 0.24 & ns \\
\hline Site $($ Protection $\times$ Island $)$ & 18 & 8827.10 & 490.39 & 0.62 & ns \\
\hline Residual & 120 & 95269.00 & 793.91 & & \\
\hline \multirow[t]{5}{*}{ Total } & 143 & $1.16 \times 105$ & & & \\
\hline & Island & $\mathbf{T}$ & p (perm) & & \\
\hline & El Hierro vs. La Palma & 0.77 & ns & & \\
\hline & El Hierro vs. Lanzarote-islets & 5.26 & ** & & \\
\hline & La Palma vs. Lanzarote-islets & 3.99 & ** & & \\
\hline
\end{tabular}


Table 2. Canonical analyses of principal coordinates (CAP) examining the effects of the factors (A) 'Protection' and (B) 'Island' on predatory fish assemblages of Diadema aff. antillarum in the Canary Islands. Percentages of the total variation explained by the first $m$ principal coordinate axes (\% Var) and allocation success or the percentage of points correctly allocated into each group are given for each analysis. Correlation coefficients for individual species ( $|r|>0.4)$ with the canonical axis for the effects of 'Protection' $\left(\mathrm{A}: \mathrm{CAP}_{1}\right)$ and 'Island' $\left(\mathrm{B}: \mathrm{CAP}_{1}\right.$ and $\mathrm{CAP}_{2}$ ) are included. $\delta^{2}$ : squared canonical correlation; MPA: marine protected area; UA: unprotected area. ${ }^{* *} \mathrm{p}<0.01$

\begin{tabular}{|c|c|c|c|c|c|c|c|c|}
\hline Factor & $m$ & $\% \operatorname{Var}$ & $\longrightarrow$ & — Allocation success (\%) & $\longrightarrow$ & & $\delta^{2}$ & $\mathrm{p}$ \\
\hline (A) Protection & & & & MPA & & Total & & \\
\hline & 6 & 68.75 & & 50.00 & & 68.75 & 0.176 & ${ }^{* *}$ \\
\hline \multirow[t]{3}{*}{ (B) Island } & & & El Hierro & La Palma Lan & zarote-islets & & & \\
\hline & 7 & 56.95 & 33.33 & 60.42 & 77.08 & 56.95 & 0.273 & ${ }^{* *}$ \\
\hline & & Negative correlation & $|r|$ & Positive correlation & $|r|$ & & & \\
\hline (A) $\mathrm{CAP}_{1}$ & & Bodianus scrofa & 0.40 & & & & & \\
\hline (B) $\mathrm{CAP}_{1}$ & & Balistes capriscus & 0.41 & & & & & \\
\hline & & Thalassoma pavo & 0.94 & & & & & \\
\hline $\mathrm{CAP}_{2}$ & & Balistes capriscus & 0.40 & Canthidermis sufflamen & 0.69 & & & \\
\hline
\end{tabular}

was more abundant at El Hierro and La Palma than at Lanzarote-islets (Table 1E, Fig. 3B). Despite the null contribution of Chilomycterus reticulata, Diplodus cervinus and D. sargus in explaining the variability of predatory fish assemblages recorded across the archipelago, data showed the low abundances of the diodontid Chilomycterus reticulata, which only occurred in the El Hierro MPA (Fig. 3C). The sparids (D. cervinus and D. sargus) were the only predatory fish recorded on all studied islands and protection levels across the archipelago, constituting, along with T. pavo, the dominant elements of assemblages at both protected and unprotected locations of Lanzarote-islets (Fig. 3B,D).

\section{Sea urchin populations and refuge utilisation}

Densities of Diadema aff. antillarum significantly differed in response to the level of protection (Table 3A); mean densities were lower in the MPAs than in the UAs, a pattern that was consistent across studied islands (Fig. 4A). The factor 'Island' significantly affected urchin density too (Table 3A). Pairwise analyses showed that the overall urchin abundances at Lanzarote-islets and La Palma were significantly higher than at El Hierro (Table 3A, Fig. 4A).

The percentage of urchins exposed in the substratum to the potential action of predators was highly variable and differed in response to factor 'Site (Protection $\times$ Island)' (Table 3B). Effects of protection were inconsistent from island to island, and the interaction 'Protection $\times$ Island' was significant (Table 3B, Fig. 4B). A posteriori analyses of the interaction only found significant differences in the percentage of exposed urchins between protection levels at La Palma (Table 3B), where higher proportions were found in non-protected locations (Fig. 4B). Urchins generally remained cryptic to a greater size and in higher proportions in the MPAs, except at El Hierro where all urchins occupied crevices (Fig. 5). In the UAs of Lanzarote and La Palma, as well as in the La Graciosa MPA, the proportion of exposed individuals tended to increase with size, despite there being some variability in the smallest sizes occurring in exposed positions (Fig. 5). In the Lanzarote UA, all juvenile sea urchins $(<20 \mathrm{~mm})$ were cryptic and most of those in the $20-30 \mathrm{~mm}$ size class also sheltered in the substratum. In comparison, in the La Graciosa MPA, Diadema aff. antillarum held on to cryptic behaviours up to a size of $40 \mathrm{~mm}$. In the La Palma UA, urchins in the small (20 to $30 \mathrm{~mm}$ ) and medium (30 to $40 \mathrm{~mm}$ ) size classes were generally cryptic, whereas in the MPA, all urchins sheltered regardless of size (Fig. 5).

Urchin population structure differed between protection levels; populations were more bimodal in MPAs, a pattern that was strongest at El Hierro and La Palma (Fig. 5). At Lanzarote-islets, size-frequency distributions appeared more unimodal both in the MPAs and UAs; however, differences were still detected between areas $\left(\chi^{2}=83.70, \mathrm{p}<0.001\right)$. The modal size of urchins in La Graciosa MPA was 52.5 to $56.0 \mathrm{~mm}$, while urchins were smaller in the Lanzarote UA (modal size: 45.5 to $49.0 \mathrm{~mm}$ ) (Fig. 5). Modal size did not differ between the UA and MPA at El Hierro or La Palma (49.0-52.5 and 42.0-45.5 mm respectively). Significant differences were found in the size distribution of urchins between the MPA and UA at La Palma $\left(\chi^{2}=\right.$ 41.50, $\mathrm{p}<0.01)$ but not at El Hierro $\left(\chi^{2}=10.41, \mathrm{p}=0.73\right)$ (Fig. 5). A second modal group consisting of mediumsized urchins (35.0 to $38.5 \mathrm{~mm}$ ) was seen at El Hierro MPA, and one consisting of larger urchins (59.5 to 61.0 $\mathrm{mm}$ ) in La Palma MPA (Fig. 5). 


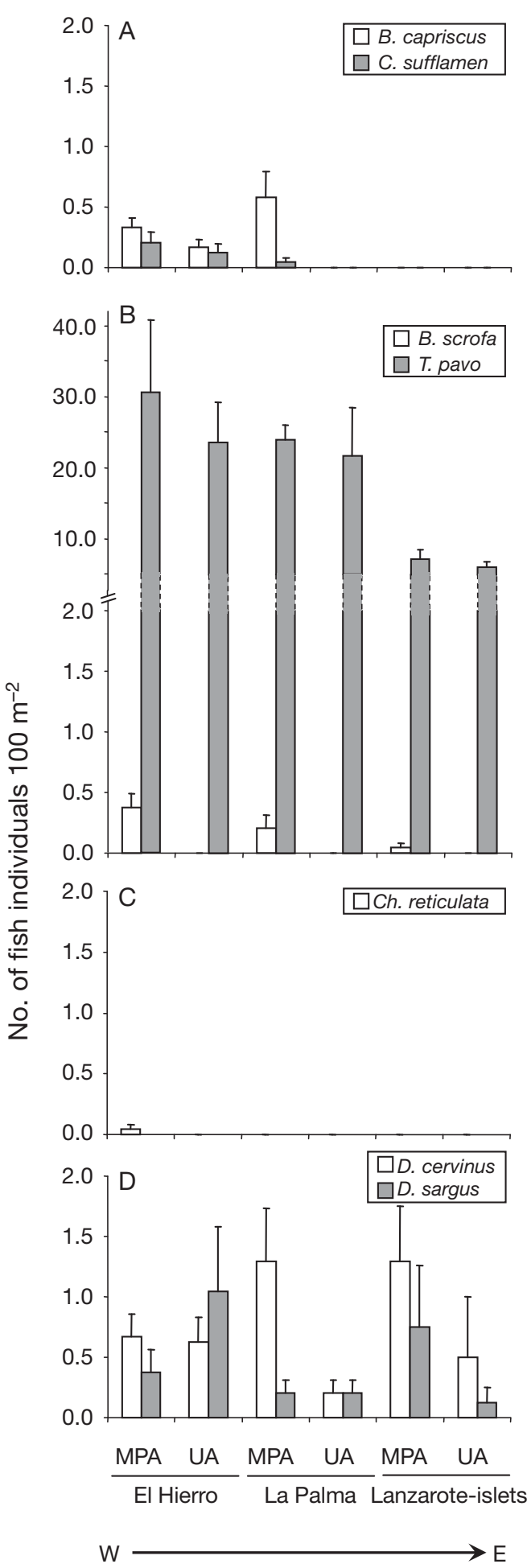

Fig. 3. Mean densities $( \pm \mathrm{SE})$ of predatory fish species of Diadema aff. antillarum within the marine protected (MPAs) and unprotected areas (UAs) on 3 islands from west (W) to east (E) in the Canary Islands: (A) the balistids Balistes capriscus and Canthidermis sufflamen, (B) the labrids Bodianus scrofa and Thalassoma pavo, (C) the diodontid Chilomycterus reticulata, and (D) the sparids Diplodus cervinus and Diplodus sargus
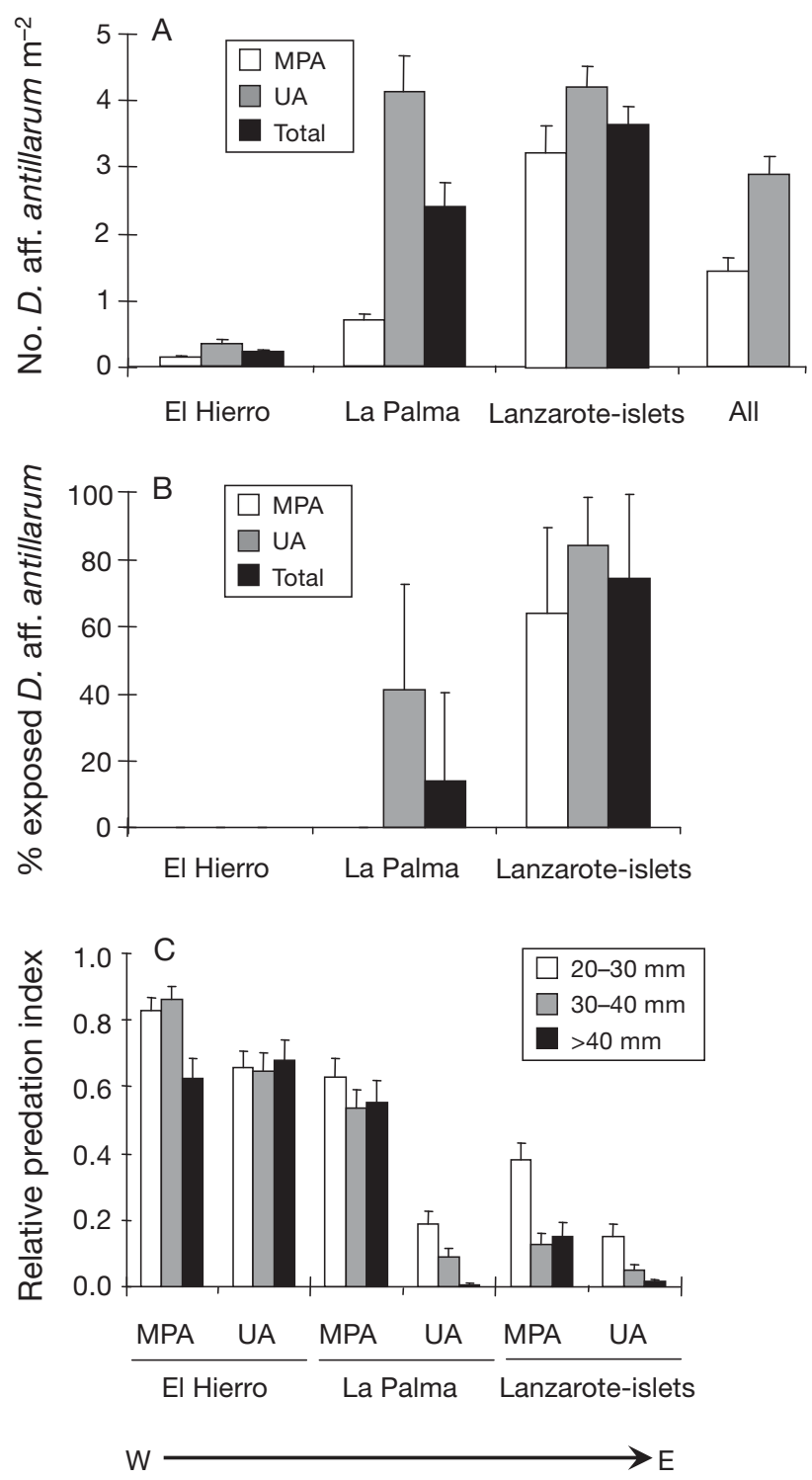

Fig. 4. Diadema aff. antillarum. (A) Mean densities $( \pm$ SE) of sea urchins, (B) mean percentages $( \pm \mathrm{SE})$ of individuals exposed on the substratum, and (C) mean relative predation index $( \pm \mathrm{SE})$ upon 3 urchin size classes obtained in predation experiments, within marine protected (MPAs) and unprotected areas (UAs) on 3 islands from west (W) to east (E) in the Canary Islands

\section{Predation levels on sea urchins}

A total of 419 Diadema aff. antillarum (out of 720 experimental individuals) were preyed upon during the experiments. In the MPAs, $72.5 \%$ of total experimental individuals were consumed, and in the UAs it was $41.7 \%$. The smallest size class of urchins (20 to $30 \mathrm{~mm}$ ) was most affected by predation, with $42.1 \%$ and $28.3 \%$ of the individuals of this size preyed upon in the MPAs and UAs respectively. In comparison, 
Table 3. Diadema aff. antillarum. Three-way distance-based permutational ANOVAs assessing differences between marine protected areas and unprotected areas, islands, and sites within each island of the Canary Islands and protection level for (A) density of sea urchins, and (B) percentage of sea urchins exposed on the substratum. (C) Four-way permutational ANOVA assessing differences in relative predation index upon sea urchins in which the factor 'Urchin size' was also included. Pairwise comparisons for significant fixed factors are included. ns: not significant; ${ }^{*} \mathrm{p}<0.05 ;{ }^{* *} \mathrm{p}<0.01$

\begin{tabular}{|c|c|c|c|c|c|}
\hline Source of variation & df & SS & MS & Pseudo- $F$ & $\mathrm{p}($ perm $)$ \\
\hline \multicolumn{6}{|l|}{ (A) Density of $D$. aff. antillarum } \\
\hline Protection & 1 & 123.15 & 123.15 & 5.22 & $*$ \\
\hline Island & 2 & 441.60 & 220.80 & 9.35 & $* *$ \\
\hline Protection $\times$ Island & 2 & 93.08 & 46.54 & 1.97 & ns \\
\hline Site (Protection $\times$ Island) & 18 & 430.39 & 23.91 & 17.76 & $* *$ \\
\hline Residual & 186 & 250.34 & 1.35 & & \\
\hline \multirow[t]{5}{*}{ Total } & 209 & 1325.10 & & & \\
\hline & \multicolumn{2}{|c|}{ Island } & $\mathbf{T}$ & \\
\hline & \multicolumn{2}{|c|}{ El Hierro vs. La Palma } & 3.03 & \multicolumn{2}{|l|}{$\operatorname{lon}_{* *}$} \\
\hline & \multicolumn{2}{|c|}{ El Hierro vs. Lanzarote-islets } & 4.86 & \multicolumn{2}{|l|}{$* *$} \\
\hline & \multicolumn{2}{|c|}{ La Palma vs. Lanzarote-islets } & 1.28 & \multicolumn{2}{|l|}{ ns } \\
\hline \multicolumn{6}{|l|}{ (B) Exposed D. aff. antillarum } \\
\hline Protection & 1 & 18363.00 & 18363.00 & 31.60 & ** \\
\hline Island & 2 & $1.77 \times 10^{5}$ & 88672.00 & 152.71 & ** \\
\hline Protection $\times$ Island & 2 & 12233.00 & 6116.30 & 10.538 & ** \\
\hline Site (Protection $\times$ Island) & 13 & 7460.00 & 573.85 & 2.67 & ** \\
\hline Residual & 165 & 35434.00 & 214.75 & & \\
\hline \multirow[t]{5}{*}{ Total } & 183 & $2.60 \times 105$ & & & \\
\hline & \multicolumn{2}{|c|}{ Protection levels within island } & $\mathbf{T}$ & \multicolumn{2}{|l|}{ p (perm) } \\
\hline & \multicolumn{2}{|c|}{ El Hierro } & $1 \times 10^{5}$ & \multicolumn{2}{|l|}{ ns } \\
\hline & \multicolumn{2}{|c|}{ La Palma } & 4.53 & \multicolumn{2}{|l|}{$*$} \\
\hline & \multicolumn{2}{|c|}{ Lanzarote-islets } & 2.83 & \multicolumn{2}{|l|}{ ns } \\
\hline \multicolumn{6}{|l|}{ (C) Relative predation index } \\
\hline Protection & 1 & 273.80 & 273.80 & 44.28 & ** \\
\hline Island & 2 & 1015.90 & 507.95 & 82.15 & $* *$ \\
\hline Urchin size & 2 & 56.10 & 28.05 & 12.64 & $* *$ \\
\hline Protection $\times$ Island & 2 & 125.18 & 62.59 & 10.12 & $* *$ \\
\hline Protection $\times$ Urchin size & 2 & 3.86 & 1.93 & 0.87 & ns \\
\hline Island $\times$ Urchin size & 4 & 18.03 & 4.51 & 2.03 & ns \\
\hline Site (Island $\times$ Protection) & 18 & 111.30 & 6.18 & 3.25 & $* *$ \\
\hline Protection $\times$ Island $\times$ Urchin size & 4 & 27.04 & 6.76 & 3.05 & $*$ \\
\hline Site (Island $\times$ Protection) $\times$ Urchin size & 36 & 79.90 & 2.22 & 1.16 & ns \\
\hline Residual & 648 & 1234.80 & 1.91 & & \\
\hline Total & 719 & 2945.90 & & & \\
\hline
\end{tabular}

$35.4 \%$ of medium-sized urchins (30 to $40 \mathrm{~mm}$ ) were preyed upon in the MPAs and $28.3 \%$ in the UAs. Also, $31.2 \%$ of urchins in the largest size class $(>40 \mathrm{~mm})$ were preyed upon in the MPAs, while it was only $15.8 \%$ in the UAs. Predation intensity was highly variable, and the interaction 'Protection $\times$ Island $\times$ Urchin size' was significant (Table 3C, Fig. 4C), indicating that the magnitude of predation intensity varied between levels of 'Protection', and was dependent on the island and urchin size considered. The difference in predation intensity between MPAs and UAs for each urchin size was most pronounced at La Palma (Fig. 4C). A posteriori analyses for the interaction revealed that predation was higher in MPAs that in UAs, except among urchins $>40 \mathrm{~mm}$ in test diameter in El Hierro, for which there were no significant differences between levels of protection (Table 4, Fig. 4C). In Lanzarote-islets MPA and UA and in La Palma UA, pairwise analyses showed that predation was significantly higher on the smallest urchins (20 to $30 \mathrm{~mm}$ ) than on any other sizes (Table 4, Fig. 4C). Predation at these locations was also more intense on 30-40 mm urchins compared to larger individuals (Table 4, Fig. 4C). In the La Palma MPA and across the whole El Hierro Island, predation intensity did not significantly differ between urchin sizes (Table 4, Fig. 4C).

The cumulative percentage of Diadema aff. antillarum preyed upon during the course of the experiments showed differences between levels of protection and islands. Over the $5 \mathrm{~d}$ experimental period, similar trends of predation were observed at the El Hierro MPA and UA, as well as at the La Palma MPA, where 
high percentages of individuals ( 50\%) were preyed upon by the second day. At La Graciosa MPA, the cumulative percentage of preyed-upon sea urchins only approached $50 \%$ by the last day of the experiment. In the La Palma and Lanzarote UAs, the percent- age of consumed individuals was low during the whole experiment $(<30 \%)$. In most cases, the fate of individuals that were preyed upon was unknown, as urchin tests were completely removed from their tethers (90.53\% of $20-30 \mathrm{~mm}$ individuals; $86.86 \%$ of $30-$

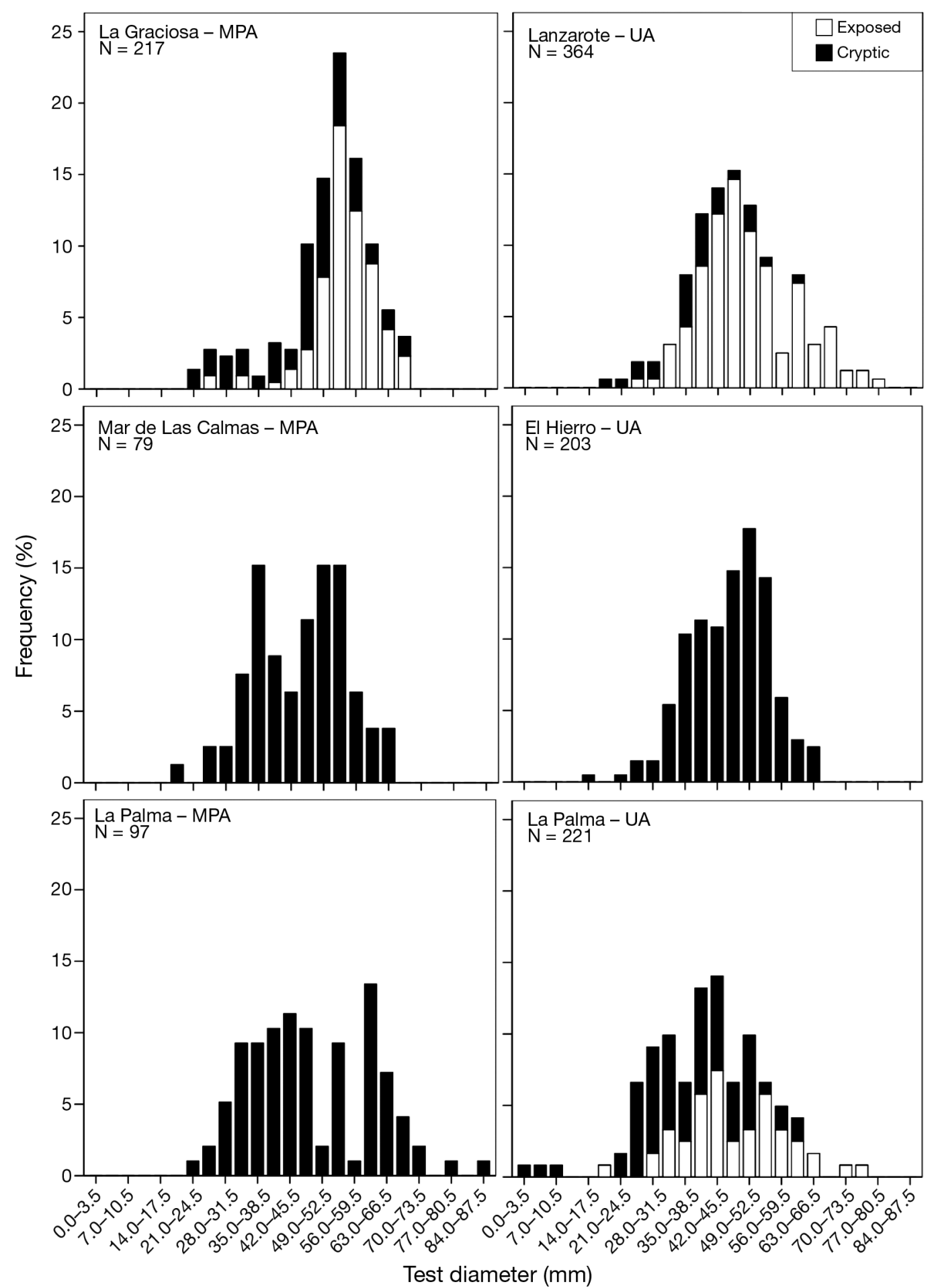

Fig. 5. Diadema aff. antillarum. Size-frequency distributions in 3 marine protected areas (MPAs) and nearby unprotected areas (UAs) in the Canary Islands. Proportions of exposed and cryptic individuals are shown 
Table 4. Diadema aff. antillarum. Pairwise analyses of relative predation index data for significant interaction of 'Protection $\times$ Island $\times$ Urchin size' in the Canary Islands found by permutational ANOVA. Comparisons were performed between (A) sea urchin size classes $(\mathrm{mm})$ for each island and level of protection and (B) protection levels for each island and urchin size class. MPA: marine protected area; UA: unprotected area; ns: not significant; ${ }^{*} \mathrm{p}<0.05 ;{ }^{* *} \mathrm{p}<0.01$

\begin{tabular}{|c|c|c|c|c|c|}
\hline $\begin{array}{l}\text { (A) Pairwise analyses } \\
\text { between size classes }\end{array}$ & $\mathrm{S} \mathrm{T}$ & $\begin{array}{c}\mathrm{p} \\
(\text { perm})\end{array}$ & $\begin{array}{l}\text { (B) Pairwise analyses } \\
\text { for MPA vs. UA }\end{array}$ & $\mathrm{T}$ & $\begin{array}{c}\mathrm{p} \\
\text { (perm) }\end{array}$ \\
\hline \multicolumn{6}{|l|}{ Lanzarote-islets } \\
\hline MPA & & & Size (mm) & & \\
\hline $20-30$ vs. $30-40$ & 2.62 & * & $20-30$ & 2.63 & * \\
\hline $20-30$ vs. $>40$ & 3.71 & * & $30-40$ & 2.92 & * \\
\hline $30-40$ vs. $>40$ & 0.54 & $\mathrm{~ns}$ & $>40$ & 4.44 & $*$ \\
\hline \multicolumn{6}{|l|}{ UA } \\
\hline $20-30$ vs. $30-40$ & 3.40 & * & & & \\
\hline $20-30$ vs. $>40$ & 5.13 & * & & & \\
\hline $30-40$ vs. $>40$ & 2.05 & ns & & & \\
\hline \multicolumn{6}{|l|}{ El Hierro } \\
\hline $20-30$ vs. $30-40$ & 0.53 & ns & $20-30$ & 2.58 & $*$ \\
\hline $20-30$ vs. $>40$ & 2.17 & ns & $30-40$ & 4.09 & $* *$ \\
\hline $30-40$ vs. $>40$ & 2.07 & ns & $>40$ & 0.37 & ns \\
\hline \multicolumn{6}{|l|}{ UA } \\
\hline $20-30$ vs. $30-40$ & 0.12 & ns & & & \\
\hline $20-30$ vs. $>40$ & 0.22 & ns & & & \\
\hline $30-40$ vs. $>40$ & 0.36 & ns & & & \\
\hline \multicolumn{6}{|l|}{$\begin{array}{l}\text { La Palma } \\
\text { MPA }\end{array}$} \\
\hline $20-30$ vs. $30-40$ & 1.56 & ns & $20-30$ & 3.93 & $* *$ \\
\hline $20-30$ vs. $>40$ & 2.85 & ns & $30-40$ & 8.36 & $* *$ \\
\hline $30-40$ vs. $>40$ & 0.40 & ns & $>40$ & 5.76 & $* *$ \\
\hline \multicolumn{6}{|l|}{ UA } \\
\hline $20-30$ vs. $30-40$ & 4.37 & ${ }^{*}$ & & & \\
\hline $20-30$ vs. $>40$ & 10.83 & $* *$ & & & \\
\hline $30-40$ vs. $>40$ & 3.64 & ${ }^{*}$ & & & \\
\hline
\end{tabular}

most scarce, while at medium to high fish densities the variability decreased and predation was maximal (Fig. 6B).

The negative exponential correlation between predation intensity and mean sea urchin density was highly significant (Fig. 6C). There was high variability in urchin density at low levels of predation; urchin density decreased sharply as predation intensity increased (Fig. 6C). The negative relationship between predation index and the percentage of exposed urchins was highly significant (Fig. 6D). Proportions of exposed individuals decreased as predation levels on the sea urchin increased (Fig. 6D).

\section{DISCUSSION}

The establishment of MPAs worldwide has the potential to significantly increase the abundance and size of commercial species (NRC 2001, Halpern 2003, Micheli et al. 2004, Guidetti 2007, Claudet et al. 2008). However, not only are these direct effects of protection achieved; the recovery of predators' populations also promotes indirect effects and interacts with variability in physical conditions and assemblages, causing shifts in community structure. For instance, increases

$40 \mathrm{~mm}$ individuals; $84.96 \%$ of $>40 \mathrm{~mm}$ individuals). In some cases, clumps of spines and fragments of carcasses were found; these mortalities were assumed to be the result of consumption by balistids (5.92\% of $20-$ $30 \mathrm{~mm}$ individuals; $8.76 \%$ of $30-40 \mathrm{~mm}$ individuals; $14.16 \%$ of $>40 \mathrm{~mm}$ individuals). Occasionally, tests were found empty, with patches of stripped spines; we attributed this to the asteroid Coscinasterias tenuispina (3.55\% of $20-30 \mathrm{~mm}$ individuals; $4.38 \%$ of $30-40 \mathrm{~mm}$ individuals; $0.88 \%$ of $>40 \mathrm{~mm}$ individuals).

\section{Relationships between predation intensity, predatory fish assemblages and urchin populations}

Predation intensity on the sea urchin was significantly and positively influenced by the total density of predatory fish found at study sites (Fig. 6A), as well as by the density of predators known to specifically target adult urchins (Fig. 6B). Predation intensity was highly variable where predatory fish of adult urchin were in abundances of predatory fish on protected coastlines have frequently been associated with a reduction in sea urchin density (Sala et al. 1998, McClanahan et al. 1999, Shears \& Babcock 2002, Guidetti 2006), with the strength of predatory control depending greatly on the environmental context (Micheli et al. 2005, Shears et al. 2008).

For several measured variables, our results indicate that there are differences between MPAs and UAs. The 3 MPAs within the Canary Islands were found to support a distinctive predatory fish assemblage, with higher densities of specific important predators such as Balistes capriscus and Bodianus scrofa, as well as higher levels of predation intensity on the sea urchin Diadema aff. antillarum, compared with respective UAs. As a result of greater predation, sea urchin densities were lower in MPAs and the urchins displayed a more cryptic behaviour within the substratum than in UAs. Through comparisons of multiple sites inside and outside several different MPAs, these results experimentally support previous evidence that predatory fish 

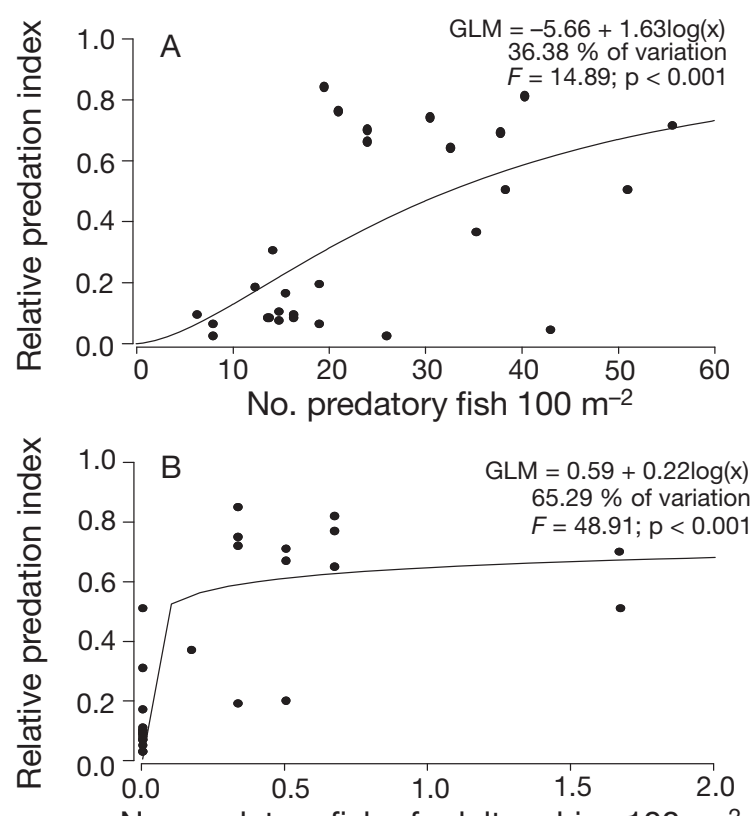

No. predatory fish of adult urchins $100 \mathrm{~m}^{-2}$
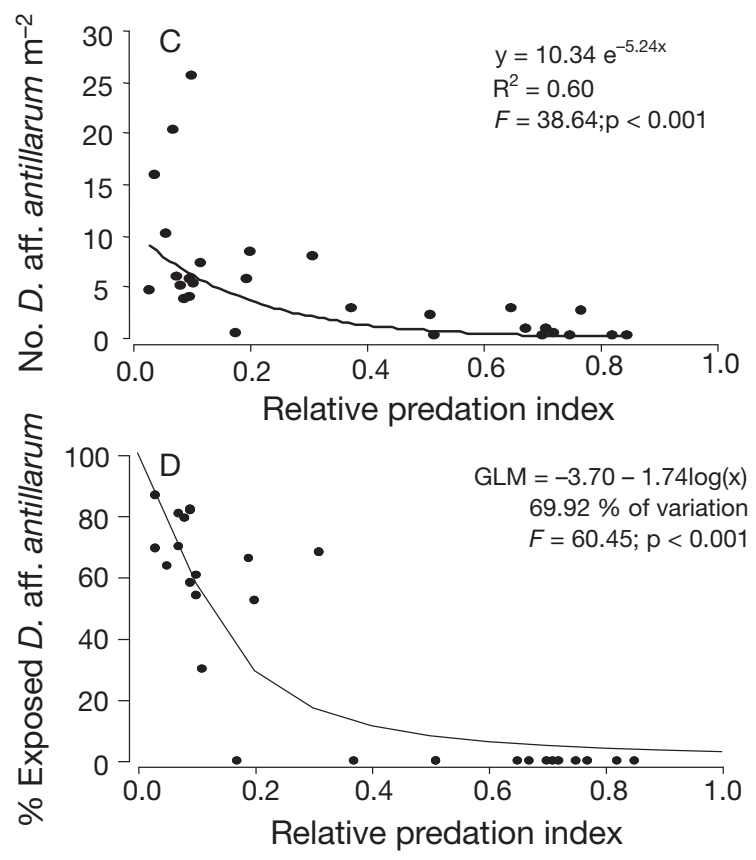

Fig. 6. Diadema aff. antillarum. Relationships between relative predation index upon the sea urchin and (A) total abundance of predatory fish, (B) abundance of predatory fish which specifically consume adult sea urchins, (C) total sea urchin density, and (D) percentage of sea urchins exposed on the substratum in the Canary Islands. Note that relative predation index is on the $y$-axis in (A) and (B) and on the $x$-axis in (C) and (D). Generalised linear models (GLM) with binomial error distribution and a logit link function were fitted in (A), (B) and (D); equations for the models based on the coefficients obtained and percentage of the overall variation are given. Regular regression techniques were used in (C). Data from Clemente et al. (2007a) obtained at highly fished areas off Tenerife are included in the analyses exert a top-down control on sea urchins in subtidal communities of the region (Clemente et al. 2009, 2010). However, more importantly, our analyses also detected variability in response between studied islands across the oceanographic gradient of the Canary Islands. When considering certain variables, such as predation index and percentage of exposed urchins, the MPA effects strongly differed among studied islands. These results suggest the importance of environmental context over the outcomes of protection measures.

Despite the general effects of protection in enhancing predatory interactions, biogeographical differences in fish communities across the oceanographic gradient of the Canarian archipelago were probably closely tied to the variations found in the response of predation and its effects to the establishment of fishing restrictions. Changes in environmental context among studied islands, such as shifts in SST that define environmental affinities of fish species, resulted in changes in predatory assemblages. Efficient predators of adult urchins (Balistes capriscus, Canthidermis sufflamen and Chilomycterus reticulata) (Clemente et al. 2010) were more common on the western islands. On the eastern islands (La Graciosa MPA and nearby Lanzarote), the abundance and composition of the predatory guild changed, and only fish that prey mainly on juvenile or small adult urchins were locally abundant, such as certain sparids (Diplodus cervinus, Diplodus sargus) and labrids (Thalassoma pavo, Bodianus scrofa) (Clemente et al. 2010). Predation levels and predatory guild composition suggested that large balistids, species very susceptible to fishing (McClanahan et al. 1999), and diodontids are more important in controlling Diadema aff. antillarum than are smaller sparids and labrids, as previously shown in other studies (McClanahan 1999, Clemente et al. 2010). Intense fishing of these key species could significantly alter the abundance and structure of sea urchin populations, especially given that sea breams and wrasses, more resistant to exploitation (McClanahan et al. 1999), fail to prey on large urchins (Clemente et al. 2010). We used a correlational approach to infer mechanistic links across trophic levels, not excluding the possibility that any links might be the result of unknown factors. However, variations in the level of urchin predation recorded across the archipelago and consistency of associated responses (e.g. cryptic behaviour) give strong evidence that predation rather than some other factor is driving differences in sea urchin abundances among islands, as has been shown for other regions (McClanahan \& Shafir 1990, Shears \& Babcock 2002, Guidetti 2006).

Size-frequency distributions of Diadema aff. antillarum support the hypothesis that fish predation also affects sea urchin population structure. In the MPAs, 
the proportion of cryptic urchins was generally larger in response to a higher predation over larger sizes, and populations had a more bimodal distribution than in the UAs. Bimodality was most clearly seen at El Hierro and La Palma MPAs. The outcome of the tethering experiments reinforce the hypothesis that bimodality in urchin populations is related to high predation on small to medium sized adult individuals, as found in protected areas around the world (Andrew \& Choat 1982, Shears \& Babcock 2002, Guidetti 2006, Pederson \& Johnson 2006). The lowest densities of $D$. aff. antillarum were recorded at El Hierro, the smallest and most isolated island with the least perturbed inshore fishery within the Canary Islands (Clemente et al. 2009), followed by abundances at La Palma MPA. These low urchin abundances were a clear indicator of high predation intensity recorded on all studied urchin sizes in these areas. At La Graciosa MPA, the size distribution showed a unimodal peak of large individuals (>50 mm), and only small adult urchins (20 to $30 \mathrm{~mm}$ ) experienced slightly higher mortality than larger sizes. However, this pattern of size-specific predation at La Graciosa MPA, associated with higher abundances of certain predatory fish species (especially of sparids and Bodianus scrofa) than in the contrasting UA, was not enough to significantly reduce urchin abundance below the threshold already known to drastically reduce erect macroalgal cover $\left(2\right.$ ind. $\mathrm{m}^{-2}$; Hernández et al. 2008a).

Attributing sea urchin mortality to different predators by examining the condition of the carcass during the course of the experiments was problematic since in many cases remains did not identify a specific predator. However, the importance of predation ascribable to balistids increased with urchin size, while mortality due to starfish predation was much more focused on small to medium sized individuals. Starfishes, sea breams and wrasses, species that typically become abundant in overexploited areas (McClanahan 1999, Shears \& Babcock 2002), were the only predators of Diadema aff. antillarum found at barren grounds around the Canary Islands (see also Clemente et al. 2007a, 2010). Given that these predators consume juvenile or small adult urchins, most predation in the UAs and in environmental contexts not favourable for balistids was largely limited to small individuals. Consequently, sea urchins showed a smaller escape size in the eastern archipelago and in heavily exploited areas, where they make up a higher proportion of individuals exposed on the substratum. Differences in patterns of D. aff. antillarum predation rate, abundance, and exposition between the 2 islands studied in the western archipelago can be explained by the interplay of the higher fishing intensity in the UA off La Palma in comparison to El Hierro (Hernández et al. 2008a), and by the relative dominance of balistid species on each island. Results of multivariate analyses showed that Balistes capriscus prevailed in La Palma while Canthidermis sufflamen, the most efficient predator of all urchin sizes (Clemente et al. 2010), was dominant in El Hierro. CAP analysis also showed a higher abundance of large Thalassoma pavo in La Palma, which could be playing an important role in controlling juvenile sea urchins. The source of sea urchin predation therefore varied according to natural and fishinginduced changes in predator assemblages.

In recent years, Diadema aff. antillarum populations have greatly increased in the Canary Islands, with dramatic consequences for the entire benthic community (Hernández et al. 2008a). Our results show that the reduction in predatory control, caused by severe overfishing in most areas of the archipelago, has likely contributed to the urchin population increase. A threshold in predation intensity appeared to activate trophic cascades that reduce urchin abundance and eventually will facilitate erect-macroalgae recovery. Other studies have also indicated a critical threshold in the abundance of predators to mediate the transition from barrens to algal beds in the Mediterranean Sea (Guidetti \& Sala 2007). However, our findings suggest that the threshold hypothesis does not apply equally to all $D$. aff. antillarum predators found within the environmental gradient of the archipelago. Not all predatory species are functionally redundant or equally efficient at controlling sea urchin abundance (Clemente et al. 2010). Therefore, the relationship between predation intensity and overall density of fish predators was weaker than that between predation and the density of fish that prey specifically on adult urchins. Only increased densities of fish capable of consuming adult sea urchins appeared to guarantee high predation levels, showing that minor increases in fish abundances can lead to significant decreases in urchin densities, as found by Harborne et al. (2009). Higher abundances of small sea urchin predators (sparids, labrids) may need to be present in order for urchin populations to be effectively controlled, as shown in other studies (Guidetti \& Dulčić 2007, Guidetti \& Sala 2007). Whether such a threshold would ever be achieved in the eastern MPA of the Canary Islands is difficult to determine, but surveys carried out along coastlines that have already been protected for several years indicate that sparids and labrids have not yet reached high enough densities. Our results show that protection will only be of benefit to control urchin populations where the environmental context inherent to each region allows key predatory species to be naturally present. Hence, context-dependent population dynamics of predatory species can produce different consequences of predation interactions in benthic 
communities, even over relatively small spatial scales. Previous studies have also concluded that simply protecting an area from fishing does not guarantee an increase in predatory fish abundance and/or related community-wide changes, unless the MPA has the appropriate ecological characteristics (Guidetti 2006, Guidetti \& Sala 2007, Shears et al. 2008).

In conclusion, the present study has revealed the importance of protection measures to enhance the strength of predatory fish activity and control sea urchin populations, despite the fact that fish-urchin interactions depend on many complex ecological variables. The incidence of fishing is widely recognised as a main issue to consider in management strategies aiming to reduce urchin density, but changes in the structure of assemblages in MPAs may follow complex successional trajectories (Halpern 2003, Micheli et al. 2004), and further long-term studies evaluating the effects of protection over time are needed. We have shown how spatially idiosyncratic factors affecting biological communities appeared to be involved in the variability of results across the environmental gradient off the Canary Islands. Therefore, context variability driven by regional or local-scale environmental gradients should not be overlooked as a factor affecting the magnitude of predatory interactions in benthic communities, especially in systems that are markedly variable at small scales.

Acknowledgements. Dedicated to the memory of J. S. Clemente Mederos. A. Rodríguez, K. Toledo, C. Sangil, J. M. Falcón, G. González, L. Martín and O. Monterroso helped in the MPAs. A. Ramos kindly provided SST satellite images. N. Aguilar and M. Johnson provided accommodation at El Hierro and the Club de Buceo Cueva Bonita in La Palma provided technical assistance. Thanks to J. Manning, who revised an earlier version of the manuscript. Three anonymous referees and the Editor greatly improved previous versions of the manuscript. S.C. and J.C.H. benefited from postgraduate fellowships ('FPU') from the Spanish Ministerio de Educación y Ciencia. This study was conducted within the framework of the project Proyecto Estructurante en Ciencias Marinas from the Agencia Canaria de Investigación, Innovacción y Sociedad de la Información.

\section{LITERATURE CITED}

Anderson MJ (2004) PERMANOVA 2factor: a FORTRAN computer program for permutational multivariate analysis of variance using permutation tests. University of Auckland. www.primer-e.com

Anderson MJ, Willis TJ (2003) Canonical analysis of principal coordinates: a useful method of constrained ordination for ecology. Ecology 84:511-525

Andrew NL, Choat JH (1982) The influence of predation and conspecific adults on the survivorship of juvenile Evechinus chloroticus (Echinoidea: Echinometridae). Oecologia 54:80-87
Barton ED, Arístegui J, Tett P, Canton M and others (1998) The transition zone of the Canary Current upwelling region. Prog Oceanogr 41:455-504

Bonaviri C, Vega Fernández T, Badalamenti F, Gianguzza P, Di Lorenzo M, Riggio S (2009) Fish versus starfish predation in controlling sea urchin populations in Mediterranean rocky shores. Mar Ecol Prog Ser 382:129-138

Bortone SA, Kimmel JJ, Bundrick CM (1989) A comparison of three methods for visually assessing reef fish communities: time and area compensated. Northeast Gulf Sci 10:85-96

Bortone SA, Van Tassell JT, Brito A, Falcón JM, Bundrick CM (1991) A visual assessment of the inshore fishes and fishery resources off El Hierro, Canary Islands: a baseline survey. Sci Mar 55:529-541

Brito A, Falcón JM, Herrera R (1995) Occurrence of the ocean triggerfish in the Eastern Atlantic (Canary Islands). J Fish Biol 47:1099-1101

Brown-Saracino J, Peckol P, Curran HA, Robbart ML (2007) Spatial variation in sea urchins, fish predators, and bioerosion rates on coral reefs of Belize. Coral Reefs 26:71-78

Claudet J, Osenberg CW, Benedetti-Cecchi L, Domenici P and others (2008) Marine reserves: size and age do matter. Ecol Lett 11:481-489

Clemente S, Hernández JC, Toledo K, Brito A (2007a) Predation upon Diadema aff. antillarum in barrens grounds in the Canary Islands. Sci Mar 71:745-754

Clemente S, Hernández JC, Brito A (2007b) An external tagging technique for the long-spined sea urchin Diadema aff. antillarum. J Mar Biol Assoc UK 87:777-779

Clemente S, Hernández JC, Brito A (2009) Evidence of the top-down role of predators in structuring sublittoral rockyreef communities in a Marine Protected Area and nearby areas of the Canary Islands. ICES J Mar Sci 66:64-71

> Clemente S, Hernández JC, Rodríguez A, Brito A (2010) Identifying keystone predators and the importance of preserving functional diversity in sublittoral rocky-bottom areas. Mar Ecol Prog Ser 413:55-67

> Falcón JM, Bortone SA, Brito A, Bundrick CM (1996) Structure of and relationships within and between the littoral, rock-substrate fish communities off four islands in the Canarian Archipelago. Mar Biol 125:215-231

Frank KT, Petrie B, Shackell NL, Choi JS (2006) Reconciling differences in trophic control in mid-latitude marine ecosystems. Ecol Lett 9:1096-1110

- Guidetti P (2006) Marine reserves reestablish lost predatory interactions and cause community effects in rocky reefs. Ecol Appl 16:963-976

> Guidetti P (2007) Potential of marine reserves to cause community-wide changes beyond their boundaries. Conserv Biol 21:540-545

> Guidetti P, Dulčić J (2007) Relationships among predatory fish, sea urchins and barrens in Mediterranean rocky reefs across a latitudinal gradient. Mar Environ Res 63:168-184

> Guidetti P, Sala E (2007) Community-wide effects of marine reserves in the Mediterranean Sea. Mar Ecol Prog Ser 335: $43-56$

> Halpern BS (2003) The impact of marine reserves: Do reserves work and does size matter? Ecol Appl 13:117-137

> Harborne AR, Renaud PG, Tyler EHM, Mumby PJ (2009) Reduced density of the herbivorous urchin Diadema antillarum inside a Caribbean marine reserve linked to increased predation pressure by fishes. Coral Reefs 28 : 783-791

> Hereu B, Zabala M, Linares C, Sala E (2004) Temporal and spatial variability in settlement of the sea urchin Paracentrotus lividus in the NW Mediterranean. Mar Biol 144: 1011-1018 
Hernández JC, Clemente S, Sangil C, Brito A (2008a) The key role of the sea urchin Diadema aff. antillarum in controlling macroalgae assemblages throughout the Canary Islands (eastern subtropical Atlantic): a spatio-temporal approach. Mar Environ Res 66:259-270

Hernández JC, Clemente S, Sangil C, Brito A (2008b) Actual status of the sea urchin Diadema aff. antillarum populations and macroalgal cover in marine protected areas compared to a highly fished area (Canary Islands-Eastern Atlantic Ocean). Aquat Conserv 18:1091-1108

- Hernández JC, Clemente S, Girard D, Pérez-Ruzafa A, Brito A (2010) Effect of temperature on settlement and postsettlement survival in a barrens-forming sea urchin. Mar Ecol Prog Ser 413:69-80

Hunt HL, Scheibling RE (1997) Role of early post-settlement mortality in recruitment of benthic marine invertebrates. Mar Ecol Prog Ser 155:269-301

Jackson JBC, Kirby MX, Berger WH, Bjorndal KA and others (2001) Historical overfishing and the recent collapse of coastal ecosystems. Science 293:629-638

Kalnay E, Kanamitsu M, Kistler R, Collins W and others (1996) The NCEP/NCAR 40-year reanalysis project. Bull Am Meteorol Soc 77:437-471

Ling SD (2008) Range expansion of a habitat-modifying species leads to loss of taxonomic diversity: a new and impoverished reef state. Oecologia 156:883-894

McClanahan TR (1995) Fish predators and scavengers of the sea urchin Echinometra mathaei in Kenyan coral-reef marine parks. Environ Biol Fishes 43:187-193

McClanahan TR (1999) Predation and the control of the sea urchin Echinometra viridis and fleshy algae in the patch reefs of Glovers Reef, Belize. Ecosystems 2:511-523

McClanahan TR, Muthiga NA (1989) Patterns of predation on a sea urchin, Echinometra mathaei (de Blainville), on Kenyan coral reefs. J Exp Mar Biol Ecol 126:77-94

McClanahan TR, Shafir SH (1990) Causes and consequences of sea urchin abundance and diversity in Kenyan coral reef lagoons. Oecologia 83:362-370

> McClanahan TR, Muthiga NA, Kamukuru AT, Machano H, Kiambo RW (1999) The effects of marine parks and fishing on coral reefs of northern Tanzania. Biol Conserv 89: 161-182

Micheli F, Halpern BS, Botsford LW, Warner RR (2004) Trajectories and correlates of community change in no-take marine reserves. Ecol Appl 14:1709-1723

Micheli F, Benedetti-Cecchi L, Gambaccini S, Bertocci I, Borsini C, Chato Osio G, Romano F (2005) Cascading

Editorial responsibility: John Choat,

Townsville, Queensland, Australia human impacts, marine protected areas, and the structure of Mediterranean reef assemblages. Ecol Monogr 75: 81-102

Nelson BV, Vance RR (1979) Diel foraging patterns of the sea urchin Centrostephanus coronatus as a predator avoidance strategy. Mar Biol 51:251-258

NRC (National Research Council) (2001) Marine protected areas: tools for sustaining ocean ecosystems. National Academy Press, Washington, DC

Pederson HG, Johnson CR (2006) Predation of the sea urchin Heliocidaris erythrogramma by rock lobster (Jasus edwardsii) in no-take marine reserves. J Exp Mar Biol Ecol 336:120-134

> Pinnegar JK, Polunin NVC, Francour P, Badalamenti F and others (2000) Trophic cascades in benthic marine ecosystems: lessons for fisheries and protected-area management. Environ Conserv 27:179-200

Power ME (1992) Top-down and bottom-up forces in food webs: Do plants have primacy? Ecology 73:733-746

- Sala E, Zabala M (1996) Fish predation and the structure of sea urchin Paracentrotus lividus populations in the NW Mediterranean. Mar Ecol Prog Ser 140:71-81

Sala E, Boudouresque CF, Harmelin-Vivien M (1998) Fishing, trophic cascades, and the structure of algal assemblages: evaluation of an old but untested paradigm. Oikos 82: $425-439$

Shears NT, Babcock RC (2002) Marine reserves demonstrate top-down control of community structure on temperate reefs. Oecologia 132:131-142

Shears NT, Babcock RC, Salomon AK (2008) Context-dependent effects of fishing: variation in trophic cascades across environmental gradients. Ecol Appl 18:1860-1873

Steneck RS (1998) Human influences on coastal ecosystems: Does overfishing create trophic cascades? Trends Ecol Evol 13:429-430

Steneck RS, Graham MH, Bourque BJ, Corbett D, Erlandson JM, Estes JA, Tegner MJ (2002) Kelp forest ecosystems: biodiversity, stability, resilience and future. Environ Conserv 29:436-459

Tuya F, Boyra A, Sánchez-Jerez P, Barbera C, Haroun RJ (2004) Relationships between rocky-reef fish assemblages, the sea urchin Diadema antillarum and macroalgae throughout the Canarian Archipelago. Mar Ecol Prog Ser 278:157-169

> Worm B, Barbier EB, Beaumont N, Duffy JE and others (2006) Impacts of biodiversity loss on ocean ecosystem services. Science 314:787-790

Submitted: December 27, 2010; Accepted: June 7, 2011

Proofs received from author(s): August 28, 2011 